\title{
ИТОГИ ПАРЛАМЕНТСКИХ ВЫБОРОВ 2019 г. В АВСТРИИ В КОНТЕКСТЕ ОБЩЕЕВРОПЕЙСКИХ ТЕНДЕНЦИЙ
}

\author{
А. В. ШАРАПО
}

Белорусский государственный университет

Минск, Республика Беларусь

В статье рассматриваются итоги досрочных выборов в парламент Австрийской Республики, которые состоялись 29 сентября 2019 г. и привели к убедительной победе консервативной Австрийской народной партии (АНП) во главе с канцлером С. Курцем. Автор выявил наиболее значимые предпосылки победы АНП в русле трансформации партийной системы Австрии в конце XX начале XXI в., обозначив важнейшие ее тенденции в контексте усиления праворадикальных и популистских настроений во всех европейских государствах. В заключение представлен прогноз относительно состава новой правящей коалиции Австрийской Республики.

Проведенное исследование представляет также особый интерес в контексте изучения общеевропейских тенденций в эволюции партийной структуры, которая сложилась во второй половине XX в. и предусматривала, как правило, борьбу за власть двух основных политических партий или блоков. На примере Австрии автор показал, что двухпартийная модель постепенно сменяется многопартийной, которая подразумевает конкуренцию нескольких крупных партий. Одним из свидетельств этого процесса является участие в формировании нового правительства австрийской «Зеленых» - партии, которая приходит на смену социал-демократам и другим традиционным левым силам Австрии.

Ключевые слова: Австрия; Австрийская народная партия (АНП); парламентские выборы; правящая коалиция; популизм и правый радикализм; электоральные тенденции.

DOI: https://doi.org/10.33581/2311-9470-2019-7-106-117.

Введение. Предысторию проведения досрочных выборов в парламент Австрии, которые состоялись 29 сентября 2019 г. и привели к новому раскладу партийных сил в этой стране, связывают с опубликованием в мае 2019 г. немецкими СМИ скандальной видеозаписи встречи лидеров Австрийской партии свободы (АПС) Х.-К. Штрахе и Й. Гуденуса с родственницей российского олигарха И. Макарова, которая якобы предлагала профинансировать некоторые партийные расходы АПС взамен на лоббирование его австрийских интересов. 
Несмотря на то, что впоследствии была выяснена постановочная суть этой записи, занимавший пост вице-канцлера председатель АПС Х.-К. Штрахе был вынужден подать в отставку и уйти с поста лидера партии. Результат этого скандала - распад правящей коалиции и решение президента страны А. Ван дер Беллена провести 29 сентября 2019 г. досрочные выборы.

Цель данной статьи - выявить новые тенденции в развитии партийной системы Австрийской Республики в контексте актуальных общеевропейских электоральных тенденций.

Хронологические рамки изучаемых событий и явлений - второе десятилетие XXI в.

Актуальность проведенного исследования исходит из важности понимания электоральных процессов в Европе, связанных с усилением популизма и правого радикализма, в том числе на примере такого значимого субъекта европейской политики, как Австрия.

Методы исследования. Исследование опирается на принципы историзма. В процессе его проведения использованы общенаучные (анализ, синтез, сравнение, обобщение, дедукция) и специальные исторические методы (историко-генетический, историко-сравнительный, историко-типологический), а также структурный и системный подходы.

Объектом исследования являются электоральные процессы в европейских государствах в начале XXI в.

Предмет исследования - трансформация партийной системы Австрийской Республики во втором десятилетии нашего века.

Обзор литературы по теме. В связи с актуальностью изучаемых электоральных процессов в Австрии, которые охватывают преимущественно период мая-сентября 2019 г., эта проблематика пока не получила должного отражения в публикациях белорусских и зарубежных исследователей, которые занимаются изучением различных аспектов истории и современного развития Австрийской Республики. Это обусловило использование материалов СМИ и актуальных аналитических обзоров, посвященных недавним событиям в Австрии.

Вместе с тем необходимо отметить, что в исторической науке Российской Федерации существует признанная научная школа, которая включает таких специалистов по истории Австрийской Республики второй половины XX в., как Г. Бордюков, Е. Грицак, К. Медведе- 
ва, В. Фрейдзон, И. Черников, А. Шарый, Я. Шимов, Ю. Юданов [1; $3 ; 4 ; 7 ; 8 ; 12 ; 13 ; 14 ; 15]$.

Важные тенденции в послевоенной истории Австрии были прослежены также в изданной в 2007 г. книге автора этой статьи «Политические системы и внешняя политика Германии, Австрии и Швейцарии» [9]. Ряд публикаций был посвящен изменениям в электоральных предпочтениях граждан ФРГ, что позволило сравнить процессы в Германии и Австрии $[10 ; 11]$.

Среди австрийских авторов, представивших наиболее полное освещение различных этапов истории этой страны, следует назвать, прежде всего, К. Воцелку, Е. Пристера, А. Райсберга, работы которых были переведены на русский язык и широко доступны современному читателю $[2 ; 5 ; 6]$.

Результаты исследования. 29 сентября 2019 г. в Австрии прошли досрочные парламентские выборы, на которых уверенную победу одержала консервативная Австрийская народная партия, набрав 37,5 процентов голосов. Далее места распределили: Социал-демократическая партия Австрии (СДПА) - 21,2 процента, правая Австрийская партия свободы - 16,2 процента, «Зеленые» - 13,9 процента и «Новая Австрия» - 8,1 процента голосов ${ }^{1}$.

Если сравнить нынешнюю общеполитическую обстановку в стране с той, которая была при выборах 2017 г., то можно отметить нынешний более благоприятный для всех партий фон. Напряженность избирательной кампании 2017 г. была вызвана рядом обстоятельств: подал в отставку лидер АНП Р. Миттерлейнер, которого сменил на этом посту молодой политик С. Курц; ушла со всех своих должностей председатель партии «Зеленых» Е. Главишник; большой и неприятной неожиданностью для других партий стало решение СДПА снять 30-летний запрет на коалицию с крайне правой АПС и декларировать готовность к сотрудничеству с ней²

Единственным сходством избирательных кампаний 2017 и 2019 гг. было то, что и тогда, и сейчас выборы проводились как дос-

\footnotetext{
${ }^{1}$ В Австрии оглашены окончательные итоги парламентских выборов // Deutsche Welle [Electronic recourse]. 2019. URL : www.dw.com/ru/в-австрии-оглашены-окончательные-итогипарламентских-выборов/а-50693123 (дата обращения : 20.10.2019).

2 Austrian Social Democrats drop ban on coalitions with far right // Reuters.com [Electronic recourse]. 2017. URL : www.reuters.com/article/uk-austria-politics-idUKKBN1951B6?il=0 (дата обращения : 20.10.2019).
} 
рочные. Однако если тогда причиной для такого решения был распад правительственной коалиции с участием социал-демократов и крайне правой АПС, то сейчас наряду с правыми в правительстве находилась Австрийская народная партия С. Курца. Как видим, выбор правых в качестве партнера по коалиции становится в Австрии характерной и показательной традицией.

Оценивая их результаты для своей партии, лидер АНП С. Курц заявил: «Мы безумно благодарны. Это невероятный успех. Мы чрезмерно счастливы и сделаем все, чтобы с уважением отнестись к этому доверию избирателей. Мы сделаем все то, что обещали. Мы пытаемся добиться взаимоуважительного сотрудничества всех партий, чтобы работать во благо Австрии» ${ }^{3}$. Если отбросить всю понятную для такой обстановки эмоциональную сторону этой фразы, то можно обратить внимание лишь на последние слова о готовности сотрудничества со всеми партиями. Ряд австрийских аналитиков, комментируя это поствыборное заявление С. Курца, от себя добавляли: «Курц готов сотрудничать со всеми партиями,... в том числе и с Австрийской партией свободы».

Кстати, эту же мысль председатель АНП повторил и после вручения ему президентом Австрии А. Ван дер Белленом мандата на формирование нового правительства, дав понять, что не исключает повторения коалиции крайне правыми.

Хотя сама по себе тема такого сотрудничества для Австрии далеко не нова, в ходе каждой избирательной кампании она выходит на передний край электоральной борьбы. Более того, эта проблема во многом определяет политический климат в стране, настроение избирателей и в конечном счете итоги выборов. При всем кажущемся официальном отторжении идеологии крайне правых именно Народная партия не раз избирала АПС в качестве своего партнера по коалиции. Конечно, во многом это объяснялось несговорчивостью более близкого идеологического партнера - Социал-демократической партии Австрии. Занимая, как правило, вторую строчку в итоговой таблице, СДПА при обсуждении возможности коалиции с АНП предъявляла порой такие требования при распределении министерских порт-

\footnotetext{
${ }^{3}$ Курц признал победу своей партии на выборах в Австрии // Беларусь сегодня [Электронный pecypc]. 2019. URL : https://www.sb.by/articles/kurts-priznal-pobedu-svoey-partii-na-vyborakh-vavstrii.html (дата обращения : 20.10.2019).
} 
фелей, на которые народники согласиться не могли, и предпочитали зачастую соглашение с АПС.

Тема о месте крайне правых в политической системе Австрии уже долгое время занимает в аналитических материалах приоритетные места.

Даже сейчас, после фактического поражения АПС на сентябрьских выборах (2017 г. - 27,4 процента, второе место; 2019 г. - 16,2 процента, третье место) никто не исключает торга с этой партией при формировании коалиции. И это не случайно. Как бы там ни было, но правые идеи в Австрии еще живы; они подпитываются чувствами «исторической гордости». Как известно, в свою бытность ее бывший лидер Й. Хайдер оправдывал нацистское прошлое Австрии и ее участие во Второй мировой войне на стороне Германии. Сейчас по понятным причинам эти лозунги уже не используются, они трансформировались в ксенофобию по отношению к иммигрантам, призывам ставить австрийские интересы превыше всего и т. п. Вот почему списывать АПС с австрийского политического поля представляется преждевременным.

Об этом говорит и история националистического движения в Европе, в котором Австрия зачастую называется его «родоначальницей» в XXI в., своеобразным реставратором крайне правых идей прошлого. Вот почему можно сказать, что корни современной правой тенденции в Европе во многом берут свое начало в Австрии. Вспомним начало XXI в., когда в ряде европейских государств отмечались вылазки неонацистов, а в некоторых странах даже образовывались неонацистские партии.

Однако в отличие от Австрии, где в 2000 г. Австрийская партия свободы сумела войти в состав правительственной коалиции с СДПА, ни одно европейское государство не решилось пойти на подобный шаг. Тогдашний лидер АПС Й. Хайдер, «будучи во власти» получил широкую возможность для пропаганды своих идей. Заметим, что тогда такой сговор с крайне правыми совершила Социал-демократическая партия Австрии как победительница выборов 1999 г. ${ }^{4}$ Она сделала это в пику социалистам других европейских стран, категорически отвергавших возможность союзных коалиций с неонацис-

\footnotetext{
4 Человек, рвущийся к власти в Австрии // Лехаим [Электронный ресурс]. 2000. URL : lechaim.ru/ARHIV/94/hider.htm (дата обращения : 20.10.2019).
} 
тами. Не стал возражать против такой коалиции и тогдашний президент Австрии от АНП Т. Клейстер.

Такое попустительство дало свои плоды. На президентских выборах 2016 г. кандидат от АПС Н. Хофер сумел не только выйти во второй тур с наилучшим результатом (36,4 процента), но и составить своему сопернику А. Ван дер Беллену (независимый кандидат, поддерживаемый партией «Зеленых») довольно сильную конкуренцию, завоевав 49,6 процента голосов 5 .

По своей активности и электоральным результатам крайне правые Австрии намного превосходили своих адептов из Франции, ФРГ, Нидерландов, Великобритании и других европейских стран. Однако постепенно свой лидерский статус на общеевропейском сегменте правых сил Австрийская партия свободы все же стала уступать другим крайне правым партиям. Если пик популярности АПС пришелся на начало XXI в. и сейчас колеблется в пределах статистических 1520 процентов, то для европейского электорального пространства крен вправо стал очевидно заметен со второго десятилетия века.

Характерна в этом плане смена парадигмы восприятия правого крена официальными кругами Евросоюза. Если в начале XXI в. сама возможность нахождения крайне правых в правительственных коалициях вызывала в высших кругах ЕС нескрываемое отторжение, то сейчас такой вариант видится ими приемлемым и при определенных обстоятельствах оправданным. Если в 2000 г. реакцией руководства Евросоюза на допуск АПС к правительственной коалиции Австрии было введение против нее экономических санкций, а со стороны ряда государств - отзыв своих послов, то сейчас (и в 2017, и в 2019 г.) «союз» АПС при формировании правительства не вызвал в Европе никакого протеста 6 . Да по-другому и быть не могло: в ФРГ уверенно набирает очки правая «Альтернатива для Германии», во Франции «Национальное объединение» Ле Пен, в Италии - партия М. Сальвини и т. д.).

Европейские правые, имея уже немалый опыт политической борьбы, демонстрируют завидное чутье электоральных настроений.

\footnotetext{
5 Кандидат от правой партии Хофер признал поражение на выборах в Австрии // РБК [Электронный ресурс]. 2016. URL : www.rbc.ru/politics/04/12/2016/584159249a7947d12cb 25c41 (дата обращения : 20.10.2019).

6 Правый сдвиг в Австрии // Иносми.ру [Электронный ресурс]. 2017. URL : inosmi.ru/politic/20171016/240526961.html (дата обращения : 20.10.2019).
} 
Лозунги эпохи крайне правого Й. Хайдера с их открытым националистическим характером сначала уступили место более мягким призывам отстаивать интересы прежде всего своего государства (даже путем выхода из Евросоюза), а затем свелись к требованиям ужесточения миграционного законодательства и защите своих интересов в европейских структурах. Характерно, что в избирательной программе АПС 2019 г. положения о выходе Австрии из ЕС уже не было. Следует отметить, что большинство партий евроскептиков в ходе последних избирательных кампаний также старались избегать призывов о выходе из Евросоюза, заменяя их лозунгами о необходимости общеевропейского объединения правых сил и невмешательстве Брюсселя во внутреннюю политику своих государств.

Например, даже такие одиозные фигуры крайне правого сектоpa, каких сейчас по новой терминологии именуют как «новые правые», М. Ле Пен и М. Сальвини в ходе избирательной кампании 2019 г. в Европарламент убеждали избирателей «не разрушать Евросоюз, а изменять его на основании здравого смысла. Результат такой трансформации в идеологии правых дал свои результаты.

Наибольшего успеха во Франции на этих выборах от правых сил добилось «Национальное объединение» М. Ле Пен, обойдя новую партию Э. Макрона «Ренессанс» и вместе с итальянской партией М. Сальвини образовав свою фракцию в Европарламенте «Европа наций и свобод» (в ее состав вошли 58 депутатов).

Другая фракция «Европа свободы и прямой демократии» (итальянские «Пять звезд», британская партия Н. Фараджа «Брекзит») получила 54 места ${ }^{7}$.

Хотя надежды правых на более полное представительство в Европарламенте не оправдались, они, по оценке аналитиков, в его работе будут играть существенную роль. Что касается австрийского представительства в этом органе, то по результатам и распределению мест оно напоминает итоги сентябрьских выборов: АНП набрала 35 процентов голосов и получила 7 мест в Европарламенте, СДПА - 23,6 процента (5 мест), АПС - 18 процентов (3 места) ${ }^{8}$. Опять-таки следу-

\footnotetext{
${ }^{7}$ Главное о результатах выборов в Европарламент // Deutsche Welle [Электронный ресурс]. 2019. URL : www.dw.com/ru/главное-о-результатах-выборов-в-европарламент/a-48892941 (дата обращения : 20.10.2019).

${ }^{8}$ Партия Курца побеждает на выборах в Европарламент в Австрии // ria.ru [Электронный реcypc]. 2019. URL : https://ria.ru/20190527/1554935143.html (дата обращения : 20.10.2019).
} 
ет обратить внимание на третье место партии Свободы с 18 процентами голосов и тремя евродепутатами - представительство для такой не очень многочисленной партии вполне удовлетворительное.

Возвращаясь к итогам сентябрьских выборов, следует обратить внимание на результаты партий второго эшелона: «Зеленые» - 13,9 процента, «Новая Австрия» - 8,1 процента голосов; в сумме - 22 процента.

Этот успех малых партий подтверждает еще одну общеевропейскую тенденцию: на электоральном поле Европы все больший вес начинают приобретать партии, программы которых лишены традиционных и привычных лозунгов центристов и отвечают на злободневные, актуальные проблемы простых избирателей (экология, климат, социальное законодательство и т. п.).

Во многом эти лозунги позволили, например «Зеленым» в ФРГ, набрать 20 процентов голосов при выборах в Европарламент, обойдя СДПГ и заняв второе место после ХДС/ХСС. В целом «Европейский свободный альянс» («Зеленые» и либералы) получили в этом органе 155 мест (для сравнения, лидер - Европейская народная партия получила 180 мест $)^{9}$.

Характерно, что рост популярности малых партий в Австрии происходит при одновременном падении доверия к право- и левоцентристским идеям. Это, в свою очередь, провоцирует отток избирателей от СДПА и частично от АНП.

Если два года назад партия «Зеленых», не преодолев четырехпроцентный барьер, даже не вошла в парламент, то сейчас к ней относятся как к одной из сильных в перспективе оппозиционных партий, способной претендовать на место в правительственной коалиции.

По словам лидеров этой партии, пятью требованиями «Зеленых» остаются: защита климата посредством развития альтернативной энергетики; равенство мужчин и женщин; образование; борьба с бедностью; интеграция иммигрантов в австрийское общество ${ }^{10}$.

\footnotetext{
9 Итоги выборов в Европарламент : усиление фрагментарности и неопределенности // Eadaily.com [Электронный ресурс]. 2019. URL : eadaily.com/ru/news/2019/06/04/itogi-vyborovv-evroparlament-usilenie-fragmentarnosti-i-neopredelennosti (дата обращения : 20.10.2019).

10 Зеленые главная оппозиционная партия Австрии // Новости политических партий России и стран СНГ [Электронный ресурс]. 2007. URL : http://www.qwas.ru/ukraine/greenparty/ id_48108/ (дата обращения : 20.10.2019).
} 
Что касается внешней политики, то «Зеленые» Австрии во многом примыкают к требованиям ряда европейских партий популистского толка, в частности, по России - об ужесточении экономических санкций, пересмотре контрактов по газопроводу «Северный поток-2» и т. Д.

На таких же внешнеполитических позициях стоит и партия «Новая Австрия», возглавляемая Б. Майнль-Райзинтер, однако, что касается возможности вхождения в коалицию с АНП, то на встрече с С. Курцем она такую вероятность категорически отвергла, обвинив его в несоблюдении фундаментальных прав человека.

Обсуждение результатов. Основные итоги и результаты проведенного исследования были изложены автором статьи в докладе «Парламентские выборы в Австрии как отражение общеевропейских электоральных тенденций» в ходе 18-й международной научной конференции «Беларусь в современном мире», проходившей на факультете международных отношений БГУ 30 октября 2019 г.

Выводы. Учитывая принципиально новую электоральную ситуацию, которая сложилась в Австрийской Республике после выборов 29 сентября 2019 г., наиболее вероятной выглядит будущая коалиция АНП с партией «Зеленых», что будет означать формирование первого в истории Австрии правительства с участием консерваторов и «Зеленых», которое в значительной степени переформатирует традиционную партийную систему Австрийской Республики.

Характеризуя итоги сентябрьских парламентских выборов в Австрии и первые заявления партийных лидеров, можно сделать вывод о сохранении этим государством своего внешнеполитического курса и внутренней политики, проводимой лидером Австрийской народной партии С. Курцем. Возможные небольшие поправки могут быть связаны с требованиями возможного партнера АНП по коалиции, колебаниями в электоральных настроениях, а также влиянием общей политики Евросоюза.

\section{Библиографические ссылки}

1. Бордюгов Г. (ред.). Советская политика в Австрии. 1945-1955 гг. : сб. док. М. : АИРОXXI; СПб. : Дмитрий Буланин, 2006. 656 с.

2. Воцелка К. История Австрии. Культура, общество, политика. М. : Весь мир, 2007. 504 с.

3. Грицак Е. Н. Тироль и Зальцбург. М. : Вече, 2007. 224 с. 
4. Медведева К. T. Австрийские Габсбурги и сословия в начале XVII века. М. : Индрик, 2004. $280 \mathrm{c}$.

5. Пристер Е. Краткая история Австрии. М. : Изд-во иностр. лит., 1952. 534 с.

6. Райсберг А. Австрия, февраль 1934. Причины и следствия. М. : Прогресс, 1975. 324 с.

7. Освободительные движения народов Австрийской империи : период утверждения капитализма / отв. ред. В. И. Фрейдзон. М. : Наука, 1981. 464 с.

8. Черников И. И. Гибель империи. М. : АСТ; СПб. : Terra Fantastica, 2002. 640 с.

9. Шарапо A. В. Политические системы и внешняя политика Германии, Австрии и Швейцарии: учеб. пособие. Минск : БГУ, 2007. $231 \mathrm{c.}$

10. Шарапо A. В. ФРГ на рубеже веков: сб. ст. Минск : БГУ, 2014. 111 с.

11. Шарапо A. B. Избирательная кампания 2017 г. в Германии: особенности межпартийной борьбы и проблемы формирования правительства : учеб. материалы для студентов. Минск : БГУ, 2018. 95 с.

12. Шарый А., Шимов Я. Австро-Венгрия: судьба империи. М. : КоЛибри, Азбука-Аттикус, 2015. $448 \mathrm{c}$.

13. Шимов Я. Австро-Венгерская империя. М. : Эксмо, 2003. 609 с.

14. Шимов Я. Австрия и Венгрия: идентичность на развалинах // Россия в глобальной политике. 2005. URL : https://globalaffairs.ru/number/n_5966 (дата обращения : 20.10.2019).

15. Юданов Ю. Австрия и Евросоюз : противостояние // МЭиМО. 2001. № 2. С. 82-91.

Дата поступления статьи: 19.09.2019.

Образец цитирования: Шарапо $A$. B. Итоги парламентских выборов 2019 г. в Австрии в контексте общеевропейских тенденций // Актуальные проблемы международных отношений и глобального развития: сб. науч. ст. Минск, 2019. Вып. 7. С. 106-117.

Автор: Шарапо Александр Викторович - доктор исторических наук, профессор кафедры международных отношений факультета международных отношений Белорусского государственного университета; e-mail: sharapa@bsu.by.

\title{
RESULTS OF THE 2019 PARLIAMENTARY ELECTIONS IN AUSTRIA IN THE CONTEXT OF PAN-EUROPEAN TRENDS
}

\author{
A. V. Sharapa \\ Belarusian State University, Minsk, Republic of Belarus
}

\begin{abstract}
The article discusses the results of the early parliamentary elections in the Austrian Republic, which took place on September 29, 2019 and led to a convincing victory for the conservative Austrian People's Party (ANP), headed by Chancellor S. Kurtz. The author identified the most significant prerequisites for the victory of the ANP in line with the transformation of the Austrian party system in the late 20th and early 21 st centuries, outlining its most important trends in the context of strengthening right wing and populist moods in all European states.
\end{abstract}


In conclusion, a forecast is presented on the configuration of the new ruling coalition of the Republic of Austria. This research is also of particular interest in the context of the study of pan-European trends in the evolution of party structure, which took shape in the second half of the XX century. It provided as a rule a struggle for power of two main political parties or blocs. On the example of Austria, the author showed that a multi partisan model, which implies the competition of several large parties, replaces gradually the former bipartisan model. One of the evidence of this process is a participation of the Greens - a party that is replacing the Social Democrats and other traditional leftist forces of Austria in the formation of the new Austrian government.

Key words: Austria; Austrian People's Party (ANP); parliamentary elections; ruling coalition; populism and right-wing radicalism; electoral trends.

\section{References}

1. Bordyugov, G. (Ed.). (2006). Sovetskaja politika v Avstrii. 1945-1955 gg.: sb. dok [The Soviet politics in Austria. 1945-1955: Collection of documents]. Moscow, AIRO-XXI; St. Petersburg, "Dmitry Bulanin", 656 p. (In Russ.).

2. Vozelka, K. (2007). Istorija Avstrii. Kul'tura, obshhestvo, politika [History of Austria. Culture, society, politics]. Moscow. Wes' Mir, 504 p. (In Russ.).

3. Gritsak, E. N. (2007). Tirol' i Zal'cburg [Tyrol and Salzburg]. Moscow, Veche, 224 p. (In Russ.).

4. Medvedeva, K. T. (2004). Avstrijskie Gabsburgi i soslovija v nachale XVII veka [Austrian Habsburgs and estates at the beginning of the XVII century]. Moscow, Indrik, 280 p. (In Russ.).

5. Prister, E. (1952). Kratkaja istorija Avstrii [A Brief History of Austria]. Moscow, Publishing House of Foreign Literature, 534 p. (In Russ.).

6. Raisberg, A. (1975). Avstrija, fevral' 1934. Prichiny i sledstvija [Austria, February 1934. Causes and effects]. Moscow, Progress, 324 p. (In Russ.).

7. Freidzon, V. I. (Ed.). (1981). Osvoboditel'nye dvizhenija narodov Avstrijskoj imperii: Period utverzhdenija kapitalizma [Liberation movements of the nations of the Austrian Empire: The period of the establishment of capitalism]. Moscow, Nauka, 464 p. (In Russ.).

8. Chernikov, I. I. (2002). Gibel' imperii [The death of the empire]. Moscow, ACT; St. Petersburg, Terra Fantastica, 640 p. (In Russ.).

9. Sharapo, A. V. (2007). Politicheskie sistemy i vneshnjaja politika Germanii, Avstrii i Shvejcarii: ucheb. posobie [Political systems and foreign policy of Germany, Austria and Switzerland: reader for students]. Minsk, BSU, 231 p. (In Russ.).

10. Sharapo, A. V. (2014). FRG na rubezhe vekov: sb. st. [Germany at the turn of the century: Collection of papers]. Minsk, BSU, 111 p. (In Russ.).

11. Sharapo, A. V. (2018). Izbiratel'naja kampanija 2017 g. v Germanii: osobennosti mezhpartijnoj bor'by i problemy formirovanija pravitel'stva: ucheb. materialy dlja studentov [The 2017 election campaign in Germany: features of the inter-party struggle and the problems of government formation: reader for students]. Minsk, BSU, 95 p. (In Russ.).

12. Shary, A., Shimov, J. (2015). Avstro-Vengrija: sud'ba imperii [Austro-Hungary: the fate of the empire]. Moscow, Kolibri, ABC-Atticus, 448 p. (In Russ.).

13. Shimov, J. (2003). Avstro-Vengerskaja imperija [Austro-Hungarian Empire]. Moscow, Eksmo, 609 p. (In Russ.). 
14. Shimov, J. (2005). Avstrija i Vengrija: identichnost' na razvalinah [Austria and Hungary: identity on the ruins]. In: Russia in global politics. № 6. URL : https://globalaffairs.ru/number/n_5966 (accessed 20.10.2019). (In Russ.).

15. Yudanov, Y. (2001). Avstrija i Evrosojuz: protivostojanie [Austria and the European Union: confrontation]. In: MEiMO. № 2, p. 82-91. (In Russ.). (In Russ.).

For citation: Sharapa, A. V. (2019). Results of the 2019 parliamentary elections in Austria in the context of pan-European trends. In: Actual problems of international relations and global development: collection of scientific papers. Minsk, Vol. 7, p. 106-117.

About author: Sharapa Aliaksandr Viktaravich - Doctor of Sciences in History (Dr. Hab.), Professor of the Department of International Relations of the Faculty of International Relations of the Belarusian State University (Minsk); e-mail: sharapa@bsu.by.

Received: 19.09 .2019 . 